\title{
Anatomia de escapos, folhas e brácteas de Syngonanthus sect. Eulepis (Bong. ex Koern.) Ruhland (Eriocaulaceae)
}

\author{
Vera Lucia Scatena ${ }^{1,3}$, Daniele Vital Vich ${ }^{1}$ e Lara Regina Parra ${ }^{2}$
}

Recebido em 16/12/2003. Aceito em 15/05/2004

\begin{abstract}
RESUMO - (Anatomia de escapos, folhas e brácteas de Syngonanthus sect. Eulepis (Bong. ex Koern.) Ruhland (Eriocaulaceae)). Estudou-se a anatomia de escapos, folhas e brácteas de 24 espécimes de Syngonanthus sect. Eulepis, que ocorrem nos campos rupestres do Brasil. Os escapos apresentam número variado de costelas, epiderme unisseriada, com células de paredes totalmente espessadas; córtex com esclerênquima e parênquima clorofiliano alternados; endoderme contínua ou descontínua; periciclo estrelado; feixes vasculares colaterais; medula com células de paredes finas ou espessadas. As folhas e as brácteas apresentam epiderme com células de paredes total ou parcialmente espessadas, estômatos na face abaxial, margem com parênquima clorofiliano ou esclerênquima; mesofilo com hipoderme constituída de esclerênquima ou parênquima aqüífero, feixes vasculares colaterais envolvidos externamente pela endoderme e internamente pelo periciclo. Escapos, folhas e brácteas de Syngonanthus sect. Eulepis apresentam células com paredes espessadas e grande quantidade de esclerênquima, provavelmente como resposta adaptativa dessas plantas ao vento e à radiação excessiva comum nos campos rupestres. Epiderme com células de paredes espessadas, estômatos com câmara subestomática não especializada, presença de hipoderme, esclerênquima, e parênquima clorofiliano compacto, caracterizam anatomicamente escapos, folhas e brácteas de Syngonanthus sect. Eulepis. No geral, os caracteres anatômicos não são consistentes para separar os táxons dentro da seção.
\end{abstract}

Palavras-chave: Eriocaulaceae, estrutura anatômica, Syngonanthus

\begin{abstract}
Anatomy of scapes, leaves, and bracts of Syngonanthus sect. Eulepis (Bong. ex Koern.) Ruhland (Eriocaulaceae)). The anatomy of scapes leaves and bracts of twenty four taxa included in Syngonanthus sect. Eulepis (Bong. ex Koern.) Ruhland from the Brazilian “campos rupestres” was studied. Scapes present a vary number of ribs, thick-walled uniseriate epidermal cells, alternate sclerenchyma, and chlorenchyma in the cortex, continuous or discontinuous endodermis, star-shaped pericycle, collateral vascular bundles, and pith with thin or thick-walled cells. Leaves and bracts have total or partial thick-walled epidermal cells, stomata on the abaxial surface, margins with chlorenchyma or sclerenchyma under the epidermis, mesophyll with hypodermis formed by sclerenchyma or aqüiferous parenchyma, and collateral vascular bundles with a double sheath: the external one, the endodermis, and the internal one, the pericycle. Thick-walled cells and sclerenchyma in the scapes, leaves, and bracts present in the species of Syngonanthus sect. Eulepis are probably a response to the typical windy and bright environment of the "campos rupestres". Features such as thick-walled epidermal cells, non-specialized substomatal chamber, presence of hypodemis, sclerenchyma, and compact chlorenchyma are typical of the Syngonanthus sect. Eulepis species. These anatomical features could be used to define the taxa in the section.
\end{abstract}

Key words: Eriocaulaceae, anatomical features, Syngonanthus

\section{Introdução}

Os campos rupestres brasileiros começaram a ser cenário para os estudos botânicos no século passado (Giulietti et al. 1987; Parra 1998). A flora de campos rupestres exibe inúmeras adaptações devidas às características do substrato que levam à necessidade de retenção de água e sobrevivência em situações extremas (Joly 1970; Moreira \& Camalier 1977). Ao longo desses campos, em especial na Cadeia do
Espinhaço (Minas Gerais e Bahia) encontra-se o centro de diversidade genética de Eriocaulaceae, família botânica típica desse ambiente. Eriocaulaceae apresenta cerca de 1.200 espécies agrupadas em dez gêneros, crescendo juntamente com Poaceae, Cyperaceae e Xyridaceae (Menezes \& Giulietti 1986; Giulietti et al. 1995).

O gênero Syngonanthus Ruhland tem distribuição disjunta na África e América do Sul (Giulietti \& Hensold 1990). Syngonanthus sect. Eulepis (Bong. ex Koern.)

\footnotetext{
1 Departamento de Botânica, Instituto de Biociências, Universidade Estadual Paulista, UNESP, C. Postal 199, CEP 13506-900, Rio Claro, São Paulo, Brasil. Bolsa CNPq

2 Departamento de Botânica, Instituto de Biociências, Universidade de São Paulo, USP, C. Postal 11461, CEP 05422-970, São Paulo, São Paulo, Brasil

3 Autor para correspondência: vscatena@rc.unesp.br
} 
Ruhland é grupo exclusivamente sul-americano. Grande parte das Eriocaulaceae comercializadas como “sempre-vivas” pertencem à Syngonanthus sect. Eulepis pelo fato de suas espécies apresentarem capítulos com brácteas involucrais vistosas (Parra 2000). A autora, em estudos taxonômicos, elaborou a redelimitação e a revisão de Syngonanthus sect. Eulepis.

Segundo Parra (comunicação pessoal) Syngonanthus sect. Eulepis é uma das cinco seções do gênero em que a delimitação da seção passou a ser questionada porque algumas espécies apresentavam caracteres que poderiam ser associados tanto a essa seção como a Syngonathus sect. Thysanocephalus.

Estudos anatômicos dos órgãos vegetativos e reprodutivos de espécies de Syngonanthus Ruhland foram realizados por Scatena et al. (1993), Scatena \& Menezes (1993; 1995; 1996a; b), Rosa \& Scatena (2003) em que os autores relacionam a presença de determinadas estruturas anatômicas com a taxonomia e a filogenia do grupo e/ou com o ambiente. Scatena \& Menezes (1996a) relataram que o número de costelas dos escapos de espécies de Syngonanthus pode auxiliar na separação das seções dentro do gênero.

Dada a importância de novos dados para uma delimitação mais natural de Syngonanthus sect. Eulepis, o objetivo deste trabalho foi caracterizar anatomicamente os escapos, as folhas e as brácteas de espécies dessa seção, visando fornecer subsídios para uma melhor delimitação da mesma, além de elucidar aspectos ecológicos do grupo.

\section{Material e métodos}

Escapos, folhas e brácteas de Syngonanthus sect. Eulepis foram retirados de espécimes de herbário, que estão depositados no Herbário do Departamento de Botânica da Universidade de São Paulo (SPF), provenientes de várias localidades do Brasil (Tab. 1). Para alguns táxons, utilizou-se também material fixado,

Tabela 1. Táxons utilizados no estudo anatômico de escapos, folhas e brácteas de Syngonanthus sect. Eulepis.

\begin{tabular}{|c|c|c|}
\hline Táxons & Localidades & Coletores \\
\hline \multirow[t]{4}{*}{ S. aciphyllus (Bong.) Ruhland } & MG - Diamantina & Isejima et al. CFCR 5609 - 16/X/1984 \\
\hline & MG - Diamantina & Isejima et al. CFCR 5609 - 16/X/1984 \\
\hline & MG - Congonhas do Norte & R.C. Forzza et al. 693 - 2/III/1998 \\
\hline & MG - Diamantina & Menezes et al. CFCR 132 - 18/VI/1980 \\
\hline \multirow[t]{2}{*}{ S. aurifibratus Silveira } & MG - Rio Pardo de Minas & R.C. Forzza et al. $791-13 / \mathrm{V} / 1998$ \\
\hline & MG - Serra do Cabral & J.R. Pirani e A. Furlan CFCR 1079 - 17/IV/1998 \\
\hline S. bahiensis Moldenke & BA - Morro do Chapéu & A. Freire-Fierro et al. 1757 - 3/X/1990 \\
\hline \multirow[t]{3}{*}{ S. bisulcatus (Koern.) Ruhland } & MG - Serra do Cabral & R.C. Forzza et al. 596 - 11/I/1998 \\
\hline & MG- Diamantina & P.T. Sano et al. 826 - 11/II/1998 \\
\hline & MG - Cristália & R. Mello Silva et al. CFCR 8957 - 6/I/1986 \\
\hline S. brasiliana Giul. & MG - Rio Vermelho & R. Mello Silva et al. 415 - 10/VI/ 1991 \\
\hline S. curralensis Moldenke & BA - Morro do Chapéu & Harley et al. SPF 23001 - 2/VI/1980 \\
\hline \multirow[t]{3}{*}{ S. dealbatus Silveira } & MG - Grão Mogol & Hensold et al. CFCR 3438 - 22/V/1982 \\
\hline & MG - Diamantina & A.M. Giulietti et al. CFCR 45 - 3/IV/1980 \\
\hline & MG - Serra do Cabral & R. Mello Silva et al. CFCR 8161 - 1/IX/1981 \\
\hline S. elegans (Bong.) Ruhland & MG - Gouveia & A. M. Giulietti et al. CFCR 4253 - 25/III/1984 \\
\hline S. elegantulus Ruhland & MG - Serro & P.T. Sano et al. 1017 - 29/VII/1999 \\
\hline S. euschemus Ruhland & GO - Serra dos Cristais & J.R. Pirani et al. 1594 - 4/II/1987 \\
\hline \multirow[t]{2}{*}{ S. giuliettiae L.R. Parra } & BA - Abaíra & W. Ganev 1375 - 26/X/1992 \\
\hline & BA - Morro do Chapéu & Harley et al. SPF 22907 - 18/VI/1980 \\
\hline S. harleyii Moldenke & BA - Umburanas & Harley et al. PDC 6141 - 9/III/1997 \\
\hline \multirow[t]{2}{*}{ S. imbricatus (Koern.) Ruhland } & SE - Serra da Itabaiana & A. Lima s.n. SPF 30381 - 2/IV/1974 \\
\hline & BA - Salvador & J.P. Souza s.n. SPF 30684 - 10/IX/1974 \\
\hline S. kegelianus (Koern.) Ruhland & PA - Oriximiná & Ferreira et al. SPF 7790 - 19/VIII/1986 \\
\hline S. lanosus L.R. Parra & BA - Piatã & P.T. Sano et al. CFCR 14457 - 23/II/1994 \\
\hline \multirow[t]{2}{*}{ S. linearis Ruhland } & MG - Lima Duarte & H.C. Sousa et al. s.n. BHCB 10916 - 18/XI/1996 \\
\hline & ES - Guarapari & W.W. Thomas et al. NY $6126-24 / \mathrm{II} / 1988$ \\
\hline S. magnificus Giul. & MG - Rio Vermelho & Isejima et al. CFCR 5513 - 14/X/1984 \\
\hline \multirow[t]{3}{*}{ S. mucugensis Giul. } & BA - Abaíra & R. Harley \& P.T. Sano 52319 - 25/II/1992 \\
\hline & BA - Mucugê & W. Ganev 827 - 12/VIII/1992 \\
\hline & BA - Abaíra & W. Ganev 2316 - 25/X/1993 \\
\hline
\end{tabular}


Tabela 1 (continuação)

\begin{tabular}{|c|c|c|}
\hline Táxons & Localidades & Coletores \\
\hline S. nitidus (Bong.) Ruhland & MG - Diamantina & J. Kraus et al. CFCR 11069 - 18/VII/1987 \\
\hline S. niveus (Bong.) Ruhland & MG - São Tomé das Letras & R. Mello Silva et al. 1601 - 21/II/1999 \\
\hline $\begin{array}{l}\text { S. paepalophyllus } \\
\quad \text { subsp. paepalophyllus Silveira }\end{array}$ & MG - Diamantina & P.T. Sano et al. 810 - 11/II/1998 \\
\hline $\begin{array}{l}\text { S. paepalophyllus } \\
\text { subsp. teretifolius L.R. Parra }\end{array}$ & BA - Abaíra & R. Harley \& B. Stannard et al. 52798 - 23/III/1992 \\
\hline S. retroflexus L.R. Parra & BA - Mucugê & A.M. Giulietti et al. CFCR 7012 - 16/XII/1984 \\
\hline S. suberosus Giul. & MG - Rio Vermelho & A.M. Giulietti et al. CFCR 4463 - 14/VII/1984 \\
\hline
\end{tabular}

CFCR - Coleção Flora dos Campos Rupestres; PDC - Coleção Plantas da Chapada Diamantina

não herborizado, coletado nos campos rupestres da Serra do Cipó e Diamantina, MG.

O estudo anatômico de escapos, folhas e brácteas das espécies de Syngonanthus sect. Eulepis foi feito a partir de material herborizado, fervido em água, com gotas de glicerina para expansão dos tecidos, e posteriormente transferido para etanol $70 \%$. As secções anatômicas foram feitas à mão livre, com lâminas de barbear, na região mediana dos escapos, das folhas e das brácteas, foram coradas com fuccina e azul de astra (Roeser 1962) e montadas em gelatina glicerinada (Kaiser 1880) entre lâmina e lamínula.

\section{Resultados}

Os escapos de Syngonanthus sect. Eulepis apresentam forma cilíndrica, simetria radiada e alguns deles estão representados, em secção transversal, nos diagramas das Figuras 1-11. Apresentam padrão anatômico constituído de epiderme, córtex e cilindro vascular.

Todos os escapos dos espécimes estudados apresentam costelas que são formadas pelo córtex. $\mathrm{Na}$ maioria dos espécimes as costelas podem apresentar esclerênquima mais parênquima clorofiliano, como em S. aurifibratus (Fig.1), S. paepalophyllus subsp. teretifolius (Fig. 2), S. dealbatus (Fig. 3), S. linearis (Fig. 5-6), S. nitidus (Fig. 7), S. kegelianus (Fig. 8), S. harleyii (Fig. 9); ou somente esclerênquima, como em S. bahiensis (Fig. 4), S. magnificus (Fig. 10) e $S$. suberosus (Fig. 11).

Os escapos podem apresentar dez costelas, como em S. suberosus (Fig. 11); seis, como em S. magnificus (Fig. 10); cinco, como em S. harleyii (Fig. 9); quatro, como em S. linearis (Fig. 5); e três, nos demais táxons, como em $S$. aurifibratus (Fig. 1) e $S$. linearis (Fig. 6). Observou-se que $S$. linearis pode apresentar indivíduos com três e com quatro costelas, conforme a população (Fig. 5-6).

A camada mais interna do córtex, a endoderme, delimita o cilindro vascular. A endoderme pode ser contínua, cilíndrica, envolvendo todos os feixes vasculares, como em S. aurifibratus (Fig. 1), S. magnificus (Fig. 10) e S. suberosus (Fig. 11); ou pode ser descontínua, formando calotas sobre os feixes menores, nos demais materiais, como em S. paepalophyllus subsp. teretifolius (Fig. 2). Em todos os materiais estudados o periciclo é estrelado, como pode ser observado naqueles das Figuras 1-11. Os feixes vasculares são colaterais e apresentam-se em dois tamanhos: os menores, mais externos, voltados ao parênquima clorofiliano, são totalmente envolvidos pelo periciclo; os maiores, mais internos, voltados ao esclerênquima, são envolvidos parcialmente pelo periciclo que forma calota sobre o floema (Fig. 1-11).

O número de feixes vasculares dos escapos pode variar de 20, como em S. suberosus (Fig. 11); para 16, como em S. magnificus (Fig. 10); dez, como em S. harleyii (Fig. 9); oito, como em S. linearis (Fig. 5-6); e seis nos demais táxons, como em S. nitidus (Fig. 7).

Todos os espécimes estudados apresentam escapo com epiderme unisseriada (E), com células de paredes totalmente espessadas, variando apenas o tamanho do lume celular, que é reduzido (Fig. 13, 17-19). Os estômatos (ET) localizam-se nas regiões em frente ao parênquima clorofiliano e apresentam câmara subestomática simples, como pode ser observado em S. paepalophyllus subsp. paepalophyllus (Fig. 13) e S. kegelianus (Fig. 17).

O córtex é constituído por esclerênquima mais parênquima clorofiliano distribuídos alternadamente em todos os espécimes estudados (Fig. 1-15, 17-19). O parênquima clorofiliano apresenta-se compacto em todos os espécimes estudados, como pode ser observado 
em S. linearis, $S$. paepalophyllus subsp. paepalophyllus, S. niveus, S. mucugensis (Fig. 12-15, respectivamente). A camada endodermóide (EN) é constituída por células de paredes finas, celulósicas, em todos os espécimes estudados, como em S. paepalophyllus subsp. paepalophyllus (Fig. 13),
S. niveus (Fig. 14), S. mucugensis (Fig. 15), S. harleyii (Fig. 19).

Internamente à endoderme está o periciclo (P) que apresenta forma estrelada, possui células de paredes espessadas, lignificadas, em todos os espécimes, como em S. paepalophyllus subsp. paepalophyllus
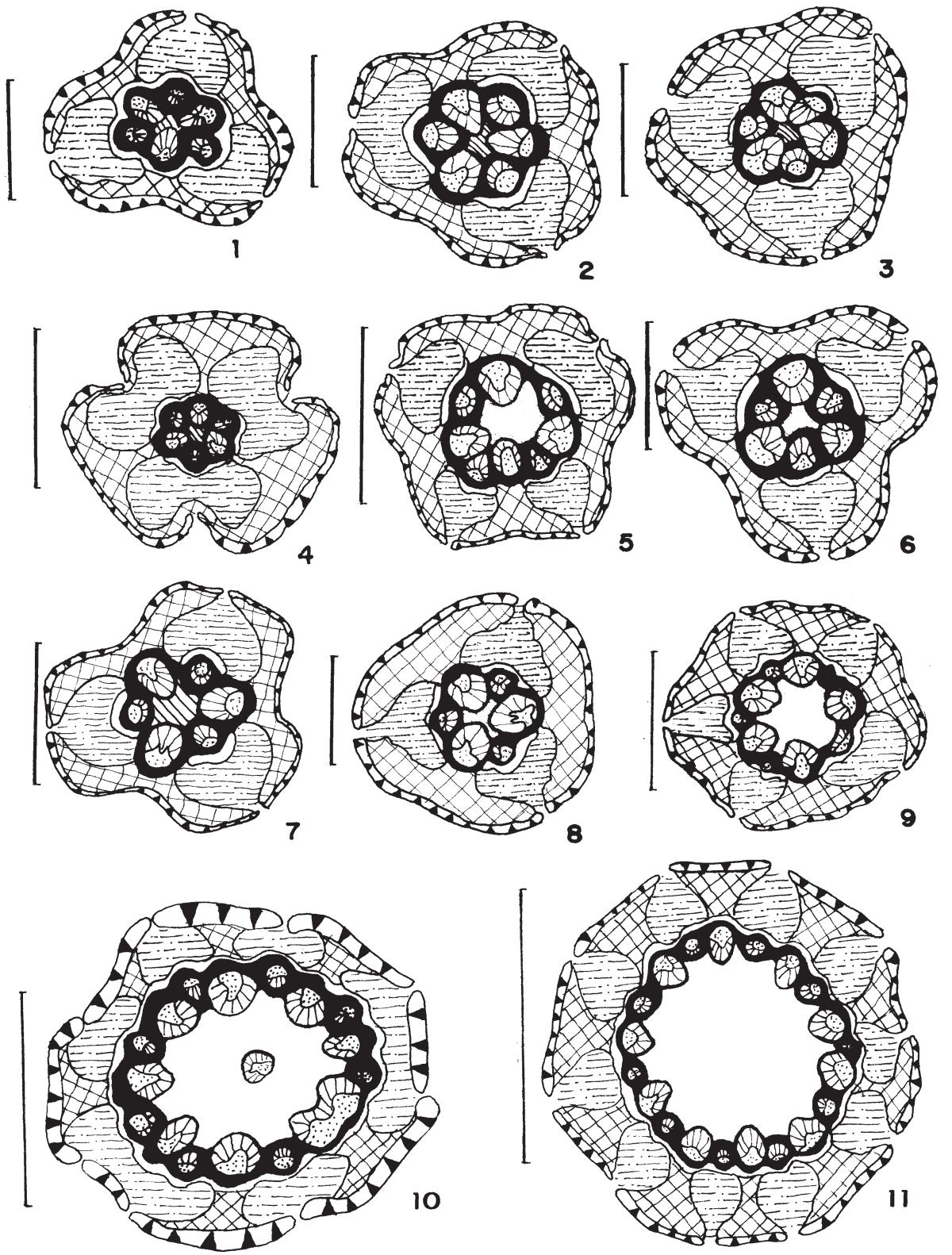

LEGENDA DOS DIAGRAMAS
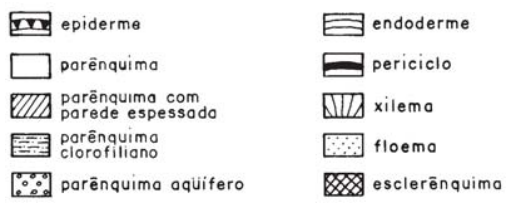

Figuras 1-11. Diagramas das secções transversais da região mediana do escapo de Syngonanthus sect. Eulepis: 1. Syngonanthus aurifibratus; 2. Syngonanthus paepalophyllus subsp. teretifolius; 3. Syngonanthus dealbatus; 4. Syngonanthus bahiensis; 5-6. Syngonanthus linearis; 7. Syngonanthus nitidus; 8. Syngonanthus kegelianus; 9. Syngonanthus harleyii; 10. Syngonanthus magnificus; 11. Syngonanthus suberosus. (Barras: Fig. 1 = 1,5mm; Fig. 2, 3, 6, 8 = 2mm; Fig. 4, 7 = 3mm; Fig. $5=5 \mathrm{~mm}$; Fig. 9 = 4mm; Fig. $10=6 \mathrm{~mm}$; Fig. $11=8 \mathrm{~mm}$ ). 
(Fig. 13), S. niveus (Fig. 14). Os feixes vasculares são colaterais e apresentam elementos de metaxilema bem desenvolvidos (Fig. 12-19). Foi observada em S. magnificus (Fig. 10,16) a presença de feixe vascular geminado (FG), no cilindro vascular; e também a presença de feixe vascular medular (FM).
A medula (M) dos escapos pode ser constituída por células parenquimáticas de paredes finas, como em S. linearis (Fig. 5-6, 12), S. kegelianus (Fig. 8), S. harleyii (Fig. 9, 19), S. magnificus (Fig. 10, 16), S. suberosus (Fig. 11), e em S. mucugensis (Fig. 15); ou pode ser constituída por células de parede
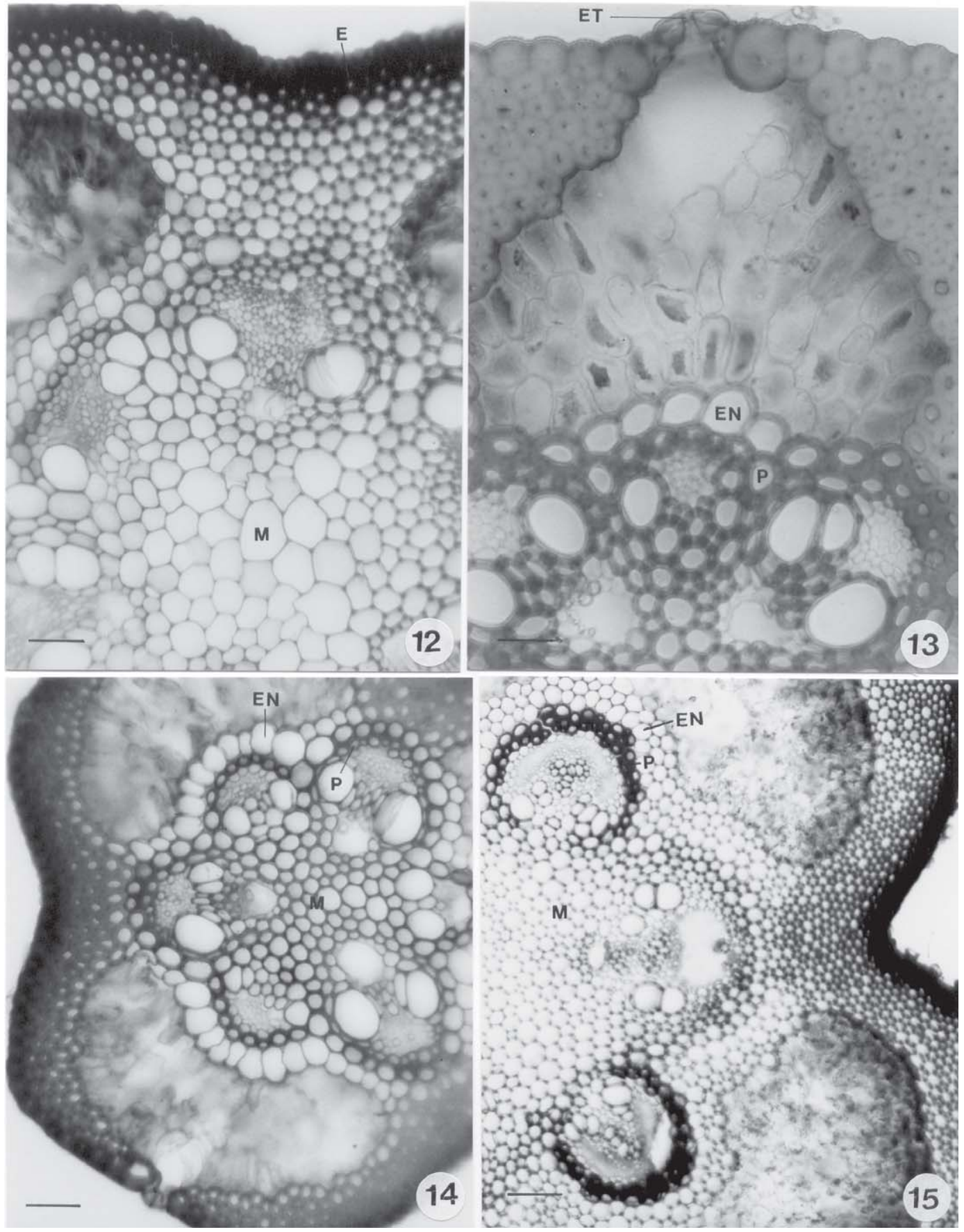

Figuras 12-15. Aspectos anatômicos de seç̧ões transversais da região mediana do escapo de Syngonanthus sect. Eulepis: 12. Syngonanthus linearis; 13. Syngonanthus paepalophyllus subsp. paepalophyllus; 14. Syngonanthus niveus; 15. Syngonanthus mucugensis. (Barras:

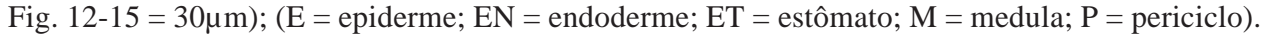


espessadas, como em S. aurifibratus (Fig. 1), S. paepalophyllus subsp. teretifolius (Fig. 2), S. dealbatus (Fig. 3), S. bahiensis (Fig. 4), S. nitidus (Fig. 7), e em S. niveus (Fig. 14).

Observa-se que as folhas dos materiais estudados apresentam padrões anatômicos semelhantes. Algumas delas podem ser observadas nos diagramas das secções transversais (Fig. 20-25), onde se vê a variação do número de feixes vasculares e a constituição da hipoderme. Observa-se ainda que a descontinuidade do mesofilo é devido à extensão das bainhas dos feixes vasculares (Fig. 20-25).
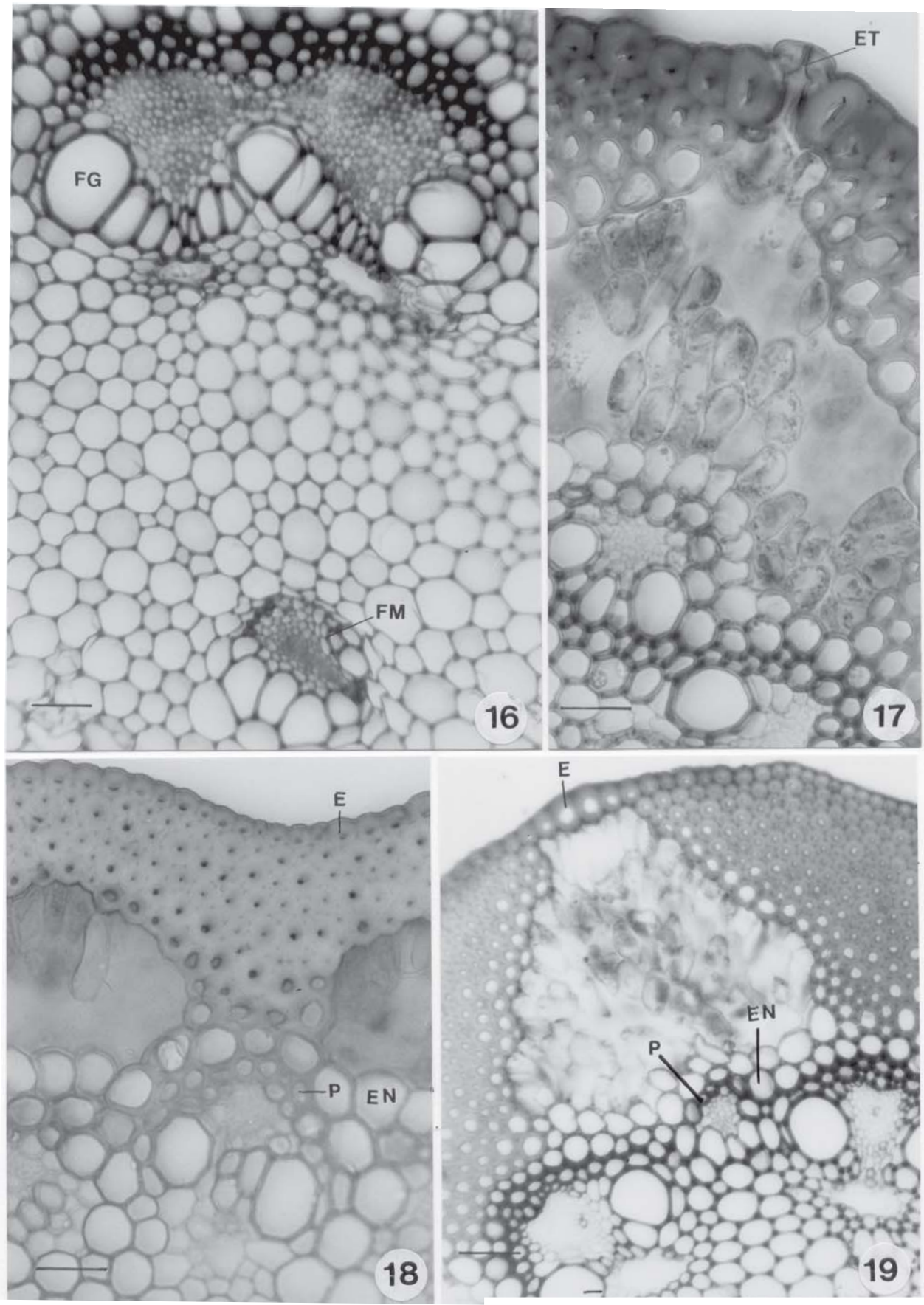

Figuras 16-19. Aspectos anatômicos de secções transversais da região mediana do escapo de Syngonanthus sect. Eulepis: 16. Syngonanthus magnificus; 17. Syngonanthus kegelianus; 18. Syngonanthus paepalophyllus subsp. teretifolius; 19. Syngonanthus harleyii. (Barras:

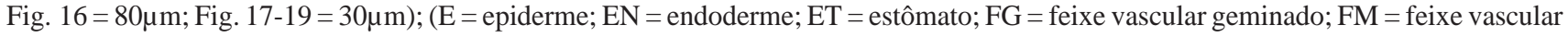
medular; $\mathrm{P}=$ periciclo). 
A epiderme (E) apresenta-se unisseriada em todos os espécimes, e possui diferentes espessamentos nas paredes das células; estas podem ser parcialmente espessadas, como em S. elegantulus, S. curralensis, S. suberosus e S. linearis (Fig. 28, 34, 35 e 37, respectivamente); ou totalmente espessadas, como em S. magnificus, S. giuliettiae, S. retroflexus, S. euschemus, S. bisulcatus, S. lanosus, S. brasiliana e S. mucugensis (Fig. 26, 27, 29, 30, 31, 32, 33 e 36, respectivamente). Os estômatos (ET) estão presentes somente na face abaxial da epiderme e não apresentam câmara subestomática especializada, como pode ser observado em S. retroflexus (Fig. 29). As folhas dos materiais estudados possuem margem que pode apresentar parênquima clorofiliano logo abaixo da epiderme, como em S. elegantulus (Fig. 20, 28), S. magnificus (Fig. 21, 26), S. bisulcatus (Fig. 31); ou esclerênquima, como em S. giulietti (Fig. 24, 27), S. retroflexus (Fig. 29), S. brasiliana (Fig. 33), S. linearis (Fig. 22, 37).

O mesofilo apresenta hipoderme, que está presente em todos os espécimes, e pode ser constituída por células de esclerênquima (ES), como em S. giuliettiae (Fig. 24, 27), S. retroflexus (Fig. 29), e S. brasiliana (Fig. 33); ou por parênquima aqüífero (PA), como em S. elegantulus (Fig. 20, 28), S. lanosus (Fig. 25, 32), S. magnificus (Fig. 21, 26), S. bisulcatus (Fig. 31), e S. mucugensis (Fig. 36). O parênquima clorofiliano é compacto em todos os espécimes estudados e apresenta de uma a duas camadas de paliçádico na
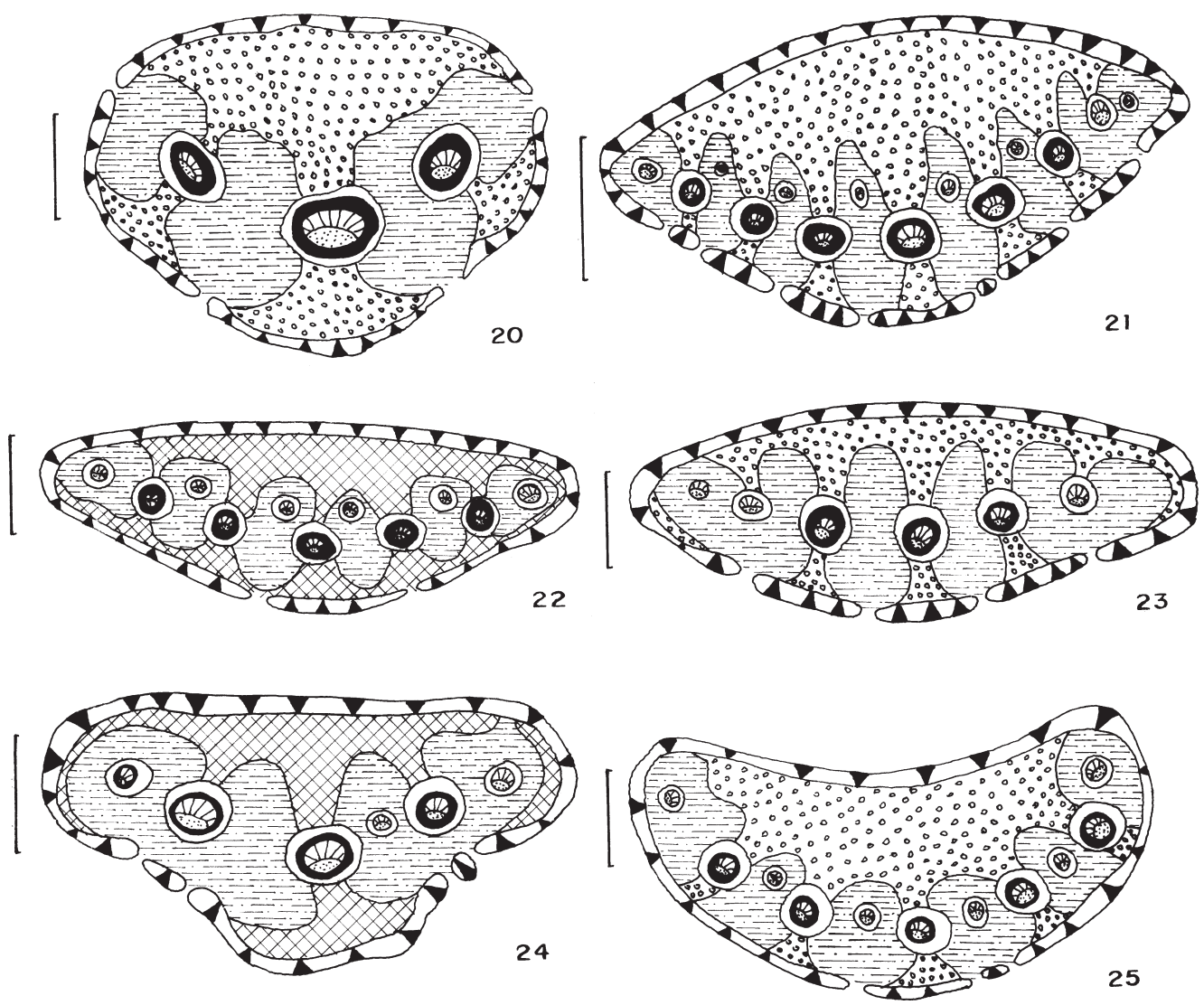

LEGENDA DOS DIAGRAMAS
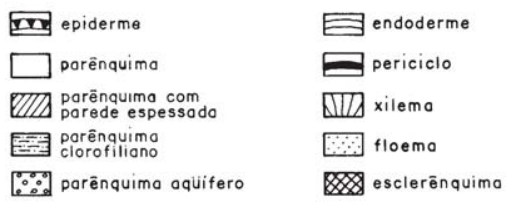

Figuras 20-25. Diagramas das secções transversais da região mediana da folha de Syngonanthus sect. Eulepis: 20. Syngonanthus elegantulus; 21. Syngonanthus magnificus; 22. Syngonanthus linearis; 23. Syngonanthus harleyii; 24. Syngonanthus giuliettiae; 25. Syngonanthus lanosus. (Barras: Fig. 20, $23=2 \mathrm{~mm}$; Fig. 21 = 4,5mm; Fig. 22, $25=$ 2,3mm; Fig. 24 = 2,5mm). 
periferia e várias camadas de lacunoso no interior, como pode ser observado em $S$. giulietti, $S$. euschemus, S. curralensis e S. suberosus (Fig. 27, 30, 34 e 35, respectivamente).

Em todos os espécimes estudados, os feixes vasculares da folha são colaterais envolvidos por bainha dupla, apresentam disposição intercalada dos maiores com os menores. A bainha externa (BE), é de natureza parenquimática, e apresenta células com paredes finas, de origem endodérmica. A bainha interna (BI) é de origem pericíclica, e apresenta células com paredes fortemente espessadas (Fig. 26-37). Ocorrem em número variado, além de serem de tamanhos diferentes, podem encontrar-se distribuídos em séries de diferentes níveis; quando isso ocorre, os maiores ficam mais próximos da epiderme abaxial (Fig. 26-37).

As brácteas de $S$. sect. Eulepis são cilíndricas e apresentam padrão anatômico semelhante ao observado nas folhas. Algumas delas estão representadas nos diagramas das secções transversais, da região mediana, nas Figuras 38-43. A face abaxial da epiderme está voltada para o exterior e a adaxial para o interior do cilindro (Fig. 38-43). Os estômatos estão presentes na face abaxial da epiderme (Fig. 38-43) e estão representados nos diagramas das figuras 38-43 através da descontinuidade da epiderme abaxial.

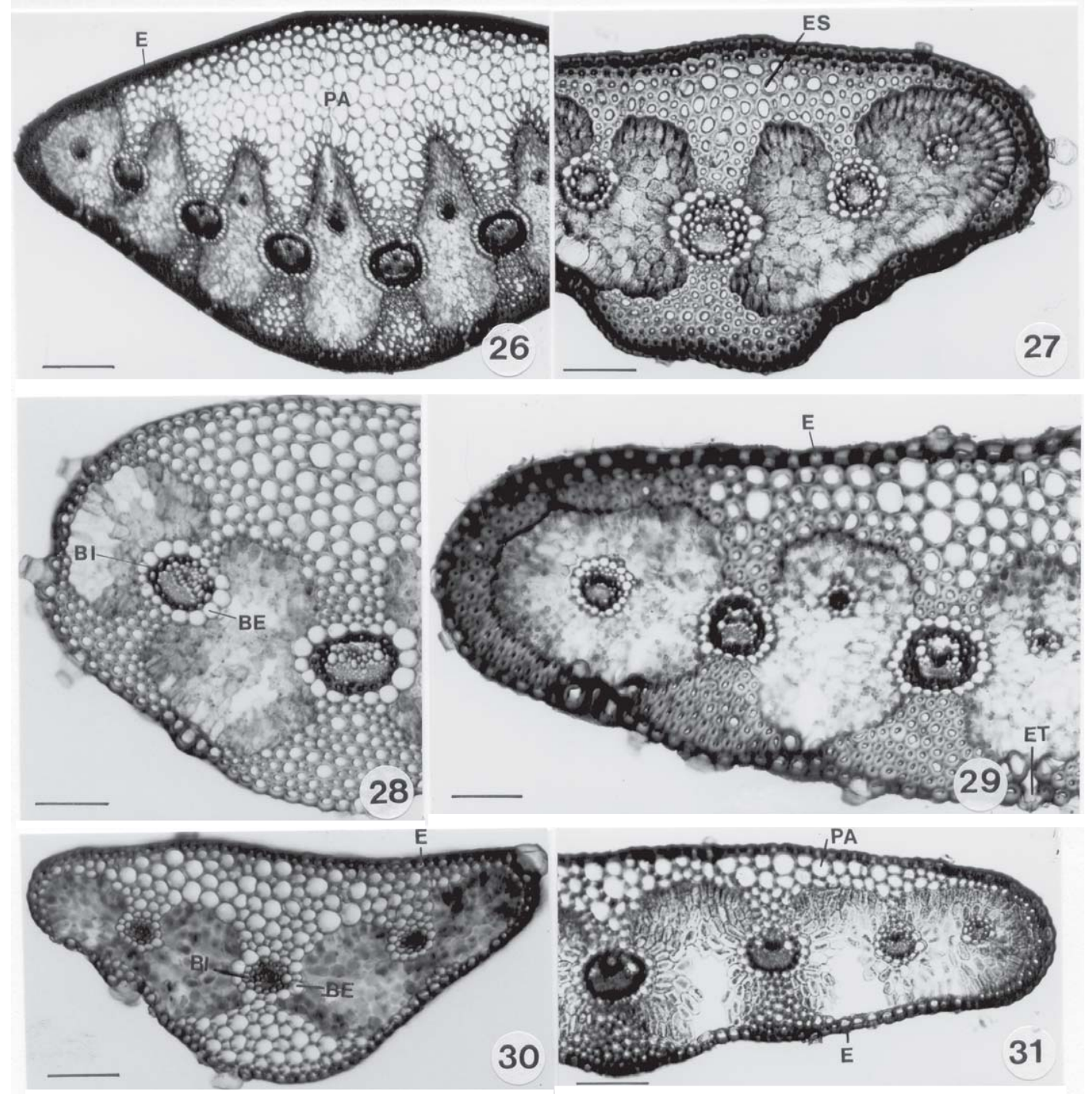

Figuras 26-31. Aspectos anatômicos de secções transversais da região mediana da folha de Syngonanthus sect. Eulepis: 26. Syngonanthus magnificus; 27. Syngonanthus giuliettiae; 28. Syngonanthus elegantulus; 29. Syngonanthus retroflexus; 30. Syngonanthus euschemus; Syngonanthus bisulcatus. (Barras: Fig. 26-31 = $80 \mu \mathrm{m})$; (BE = bainha externa; BI = bainha interna; E = epiderme; ES = esclerênquima; ET = estômato; $\mathrm{PA}$ = parênquima aqüífero). 

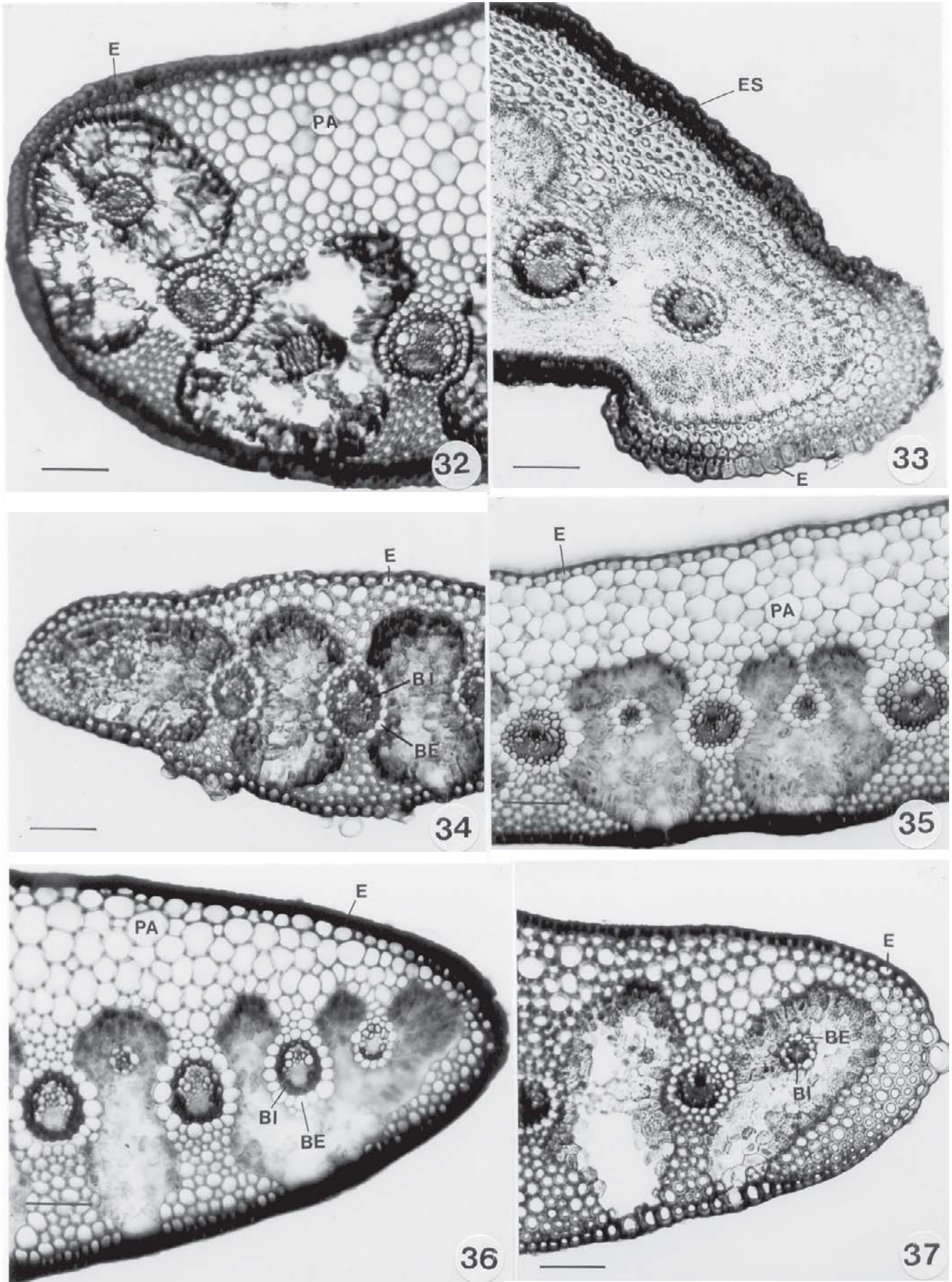

Figuras 32-37. Aspectos anatômicos de secções transversais da região mediana da folha de Syngonanthus sect. Eulepis: 32. Syngonanthus lanosus; 33. Syngonanthus brasiliana; 34. Syngonanthus curralensis; 35. Syngonanthus suberosus; 36. Syngonanthus mucugensis; 37. Syngonanthus linearis. (Barras: Fig. 32-37 = $80 \mu \mathrm{m})$; $(\mathrm{BE}=$ bainha externa; BI = bainha interna; $\mathrm{E}$ = epiderme; $\mathrm{ES}$ = esclerênquima; PA = parênquima aqüífero). 
O mesofilo apresenta hipoderme constituída de parênquima aqüífero, como em S. curralensis (Fig. 40) e S. niveus (Fig. 43); ou esclerênquima, como em S. elegans (Fig. 38), S. linearis (Fig. 39), S. bisulcatus (Fig. 41) e S. paepalophyllus subsp.
Paepalophyllus (Fig. 42). O parênquima clorofiliano é intercalado com os feixes vasculares, que são colaterais, envolvidos por bainha dupla, que ocorrem em número sete, como em S. bisulcatus (Fig. 41), ou seis, como nas demais espécies (Fig. 38-40, 42-43).
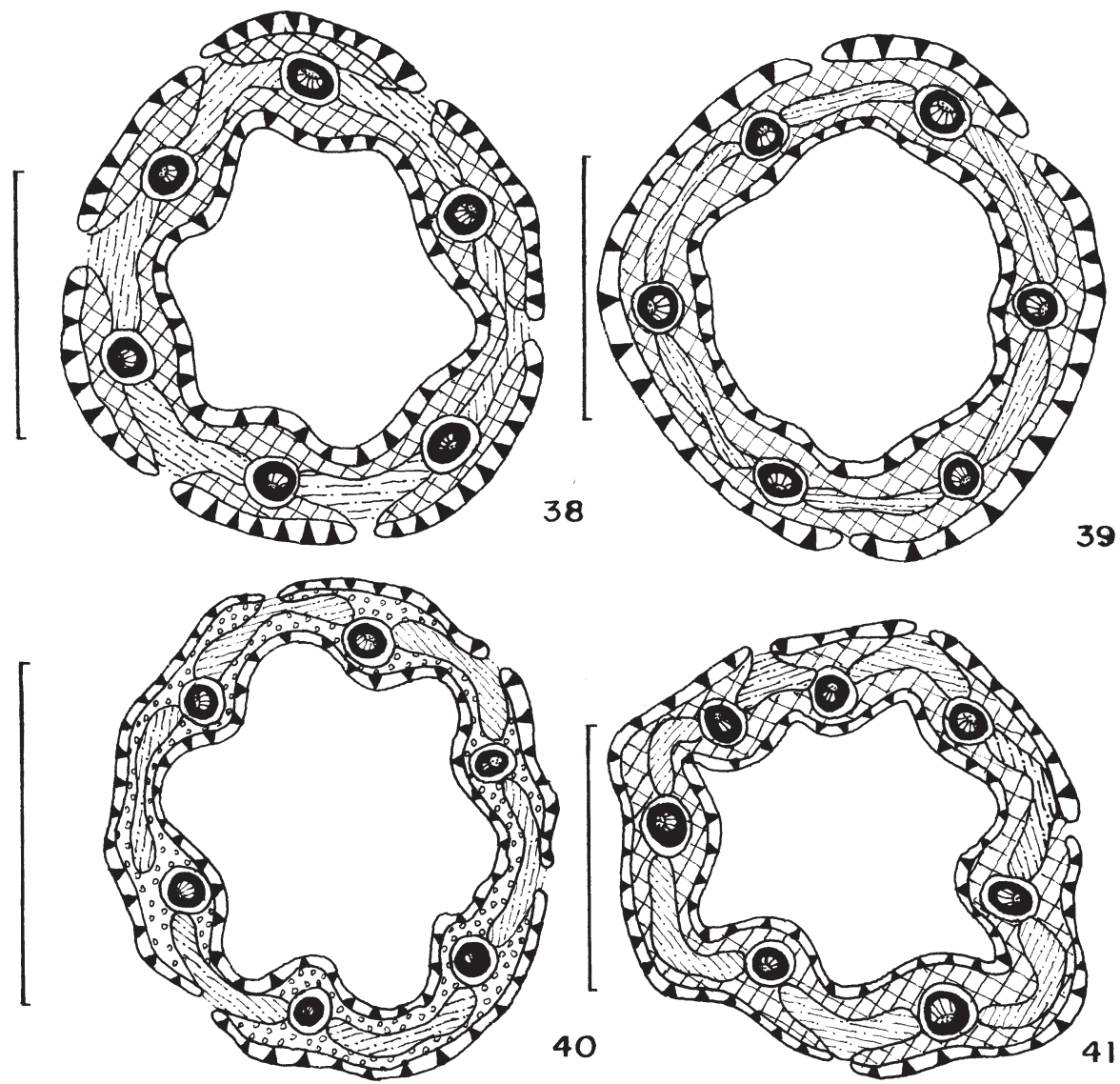

LEGENDA DOS DIAGRAMAS
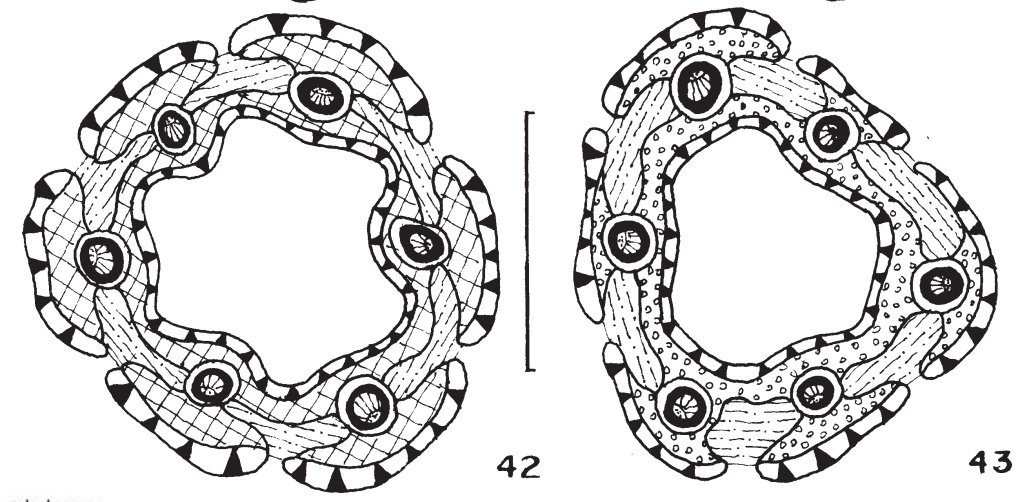

\section{epiderme endoderme

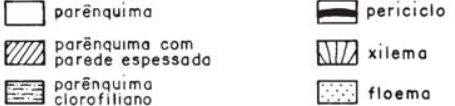

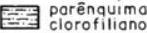

$\because \because$ parênquimo oquifero

esclerēnquima

Figuras 38-43. Diagramas das secções transversais da região mediana da bráctea de Syngonanthus sect. Eulepis: 38. Syngonanthus elegans; 39. Syngonanthus linearis; 40. Syngonanthus curralensis; 41. Syngonanthus bisulcatus; 42. Syngonanthus paepalophyllus subsp. paepalophyllus; 43. Syngonanthus niveus. Os estômatos estão representados através da descontinuidade da epiderme abaxial. (Barras: Fig. 38 = 4,5 mm; Fig. 39 = 6,5 mm; Fig. 40 = 12 mm; Fig. $41=7$ mm; Fig. 42 = 5 mm; Fig. $43=6$ mm). 


\section{Discussão}

Os espécimes de Syngonanthus sect. Eulepis estudados neste trabalho apresentam as células epidérmicas dos escapos com paredes totalmente espessadas e lume reduzido. Segundo Scatena \& Menezes (1996a), alguns táxons de Syngonanthus apresentam-nas com paredes parcialmente espessadas, enquanto outros apresentam-nas com paredes finas, principalmente naqueles que ocorrem em ambientes úmidos ou aquáticos.

Epiderme com células totalmente espessadas também foi observada em várias populações de Leiothrix crassifolia (Bong.) Ruhland (Scatena \& Giulietti 1996) e em outras Eriocaulaceae, principalmente naquelas que ocorrem em ambientes secos, portanto xeromórficas, como a maioria das espécies estudadas de Paepalanthus e Syngonanthus dos campos rupestres. O xeromorfismo nas partes aéreas de Eriocaulaceae é uma resposta adaptativa dessas plantas, que crescem expostas aos ventos fortes e à alta intensidade luminosa constantes nos campos rupestres brasileiros.

Os escapos das Eriocaulaceae estudadas possuem estômatos que ocorrem nas regiões intercostais. Para Syngonanthus, a presença ou ausência de câmara subestomática especializada é uma estrutura anatômica importante para caracterizar as seções dentro do gênero. Syngonanthus sect. Eulepis não apresenta câmara subestomática especializada. Em todos os táxons da seção de Thysanocephalus a câmara subestomática especializada está presente, como foi demonstrado por Scatena \& Menezes (1996a).

Além do espessamento das células da epiderme, os escapos apresentam, no córtex, esclerênquima associado ao parênquima clorofiliano, formando as costelas. Algumas espécies apresentaram costelas constituídas somente por esclerênquima. A presença de epiderme com células de paredes espessadas associada ao tecido de sustentação permite que os escapos fiquem enrijecidos e, assim, sustentem os capítulos no seu ápice.

Os escapos dos espécimes de Syngonanthus sect. Eulepis estudados não apresentam parênquima aqüífero no córtex, e sim esclerênquima. Segundo Scatena \& Menezes (1996a), a presença de parênquima aqüífero no córtex é característica marcante para as espécies da seção Thysanocephalus, enquanto os resultados deste trabalho mostram que a presença de esclerênquima no córtex é característica marcante para as espécies de Syngonanthus sect. Eulepis.
O número de costelas do escapo é freqüentemente usado como carater taxonômico para a classificação das espécies de Eriocaulaceae (Giulietti et al. 1998). Segundo Parra (comunicação pessoal) as espécies de Syngonanthus sect. Eulepis apresentam três costelas evidentes ou pouco evidentes. No presente trabalho foram observados táxons nos quais o número de costela variou de três, quatro, cinco, seis ou dez. Esse fato pode ser explicado pela variação que ocorre dentro da população, uma vez que no presente trabalho foram analisados indivíduos de populações de três localidades diferentes.

Os escapos de Leiothrix crassifolia (Bong.) Ruhland também podem apresentar de três a oito costelas aleatoriamente, de acordo com a distribuição geográfica de suas populações, não sendo considerado, portanto um bom caráter para a classificação do táxon (Scatena \& Giulietti 1996). Com isso, supõe-se que, também aqui, para os táxons da seção Eulepis, o número de costelas não seja um bom caráter para a separação das espécies, uma vez que este varia dentro das populações.

Para Syngonanthus sect. Eulepis, Parra (comunicação pessoal) afirmou que não há evidências de variação intra-específica, mas de acordo com os resultados obtidos neste trabalho, observam-se variações em Syngonanthus linearis que, de acordo com a localização geográfica, apresentou três ou quatro costelas, confirmando o que foi discutido acima e concluindo que o caráter, número de costelas, não é consistente para separar as espécies dentro da seção.

Em Syngonanthus magnificus foi encontrado um feixe vascular medular e um feixe vascular geminado. Tais características nunca haviam sido referidas para Syngonanthus sect. Eulepis. Feixes vasculares medulares foram referidos por Scatena et al. (1998) para algumas espécies de Paepalanthus subg. Platycaulon sect. Conferti. Talvez esta característica, que ocorre esporadicamente em grupos taxonômicos diferentes, não seja um bom caráter taxonômico. Estudos posteriores poderão dar nova luz à interpretação dessa ocorrência.

Com relação às folhas e às brácteas, os táxons de Syngonanthus sect. Eulepis apresentam células com paredes espessadas tanto na epiderme como na hipoderme. A presença de células com paredes espessadas é aspecto notadamente xeromórfico para Syngonanthus (Scatena \& Menezes 1996a). Esta característica também foi observada em outras plantas de campos rupestres, como nas Compositae (Handro et al. 1970; Sajo \& Menezes 1994), Velloziaceae 
(Menezes 1971; 1975), Iridaceae (Chueiri-Chiaretto 1984) e Xyris (Sajo 1992).

Dentro de Eriocaulaceae, esse caráter foi observado em Paepalanthus (Castro \& Menezes 1995), Leiothrix crassifolia (Scatena \& Rocha 1995) e Syngonanthus (Scatena \& Menezes 1996a). Segundo Pyykkö (1966), esse espessamento deve estar relacionado com ambientes secos e pode proteger a folha contra a transpiração e a luminosidade excessivas. Essas considerações podem ser feitas também para Syngonanthus sect. Eulepis que cresce nos campos rupestres e fica continuamente exposta à alta luminosidade. Além disso, concorda-se com Scatena \& Menezes (1996a) que esse caráter também pode atuar como suporte mecânico contra a ação dos ventos que são constantes nesse ecossistema.

Em todos os espécimes estudados neste trabalho, os estômatos apresentam-se somente na face abaxial das folhas. Segundo Parkhurst (1978), essa característica é mais comum em plantas de regiões úmidas do que secas. Concorda-se aqui com Scatena \& Menezes (1996a) que comentam que tal fato está mais ligado a possíveis relações filogenéticas do que a problemas ecológicos, pois as espécies de Syngonanthus sect. Eulepis crescem em região seca, pelo menos na maior parte do ano.

Nas folhas e brácteas de Syngonanthus sect. Eulepis os estômatos apresentam câmara subestomática sem qualquer artifício, como na maioria das outras plantas da família. Essa característica também ocorre em Syngonanthus sect. Dimorphacaulon e Syngonanthus sect. Carphocephalus (Scatena \& Menezes 1996a). Dentre as seções de Syngonanthus, apenas as espécies de Syngonanthus sect. Thysanocephalus apresentam estômatos com câmara subestomática especializada, que é multicompartimentada (Scatena \& Menezes 1993; 1996a).

A margem da folha nas espécies estudadas é constituída por parênquima clorofiliano ou esclerênquima abaixo da epiderme. A presença ou ausência de tecido de sustentação sob a epiderme pode ser considerada caráter importante para a taxonomia das Eriocaulaceae. Esse caráter foi utilizado para distinguir diferentes populações de Leiothrix flavescens (Bong.) Ruhland (Giulietti et al. 1998). Para Syngonanthus sect. Eulepis esse caráter varia mesmo dentro das populações.

Todos os espécimes de Syngonanthus sect. Eulepis apresentam escapos, folhas e brácteas com hipoderme que pode ser constituída de esclerênquima ou parênquima aqüífero. Scatena \& Menezes (1996a), em estudos de desenvolvimento das folhas de Syngonanthus, verificaram tratar-se realmente de hipoderme. A presença de hipoderme constituída de parênquima aqüífero tem papel importante no armazenamento e transporte de água (Tomlinson 1969). A presença de parênquima aqüífero em plantas de ambiente seco, associada com outras características xeromórficas, lhes permite o armazenamento de água, segundo Koller \& Rost (1988) e Scatena \& Menezes (1996a).

Syngonanthus sect. Eulepis apresenta mesofilo compacto, em contrapartida, as demais seções de Syngonanthus, como Thysanocephalus, Dimorphocaulon e Carphocephalus apresentam mesofilo frouxo na maioria das espécies. Essas características estão diretamente relacionadas ao ambiente no qual as espécies de cada grupo taxonômico descrito acima cresce. Segundo Scatena \& Menezes (1996a) para espécies de Syngonanthus, mesofilo frouxo é característico de plantas de ambientes úmidos, enquanto mesofilo compacto é característico de plantas de ambientes secos, corroborando os resultados obtidos neste trabalho, pois Syngonanthus sect. Eulepis crescem na areia onde a água escoa rapidamente.

De acordo com os resultados obtidos neste trabalho e com aqueles disponíveis na literatura, verifica-se que Syngonanthus sect. Eulepis apresenta a estrutura anatômica básica encontrada nas Eriocaulaceae que crescem em ambientes secos. Verifica-se que os espécimes dos diferentes táxons apresentam adaptações ambientais xeromórficas, tais como: células epidérmicas com paredes espessadas, presença de hipoderme, presença de parênquima aqüífero e mesofilo compacto.

Observou-se pelos dados obtidos neste trabalho que epiderme com células de paredes espessadas, estômatos com câmaras subestomáticas não especializadas, presença de hipoderme, esclerênquima, parênquima aqüífero e parênquima clorofiliano compacto caracterizam anatomicamente escapos, folhas e brácteas de Syngonanthus sect. Eulepis. No geral, os caracteres anatômicos de Syngonanthus sect. Eulepis não são consistentes para separar os táxons, mas sim para caracterizá-los dentro da seção.

Dentre as seções de Syngonanthus, Syngonanthus sect. Thysanocephalus são as espécies que mais se aproximam de Syngonanthus sect. Eulepis pelas carcterísticas anatômicas das folhas (Scatena \& Menezes 1996a). Essa sugestão pode ser confirmada com os resultados obtidos no presente trabalho. Por outro lado, a presença de câmara 
subestomática especializada (multicompartimentada) em Syngonanthus sect. Thysanocephalus é a característica anatômica que mais as diferencia de Syngonanthus sect. Eulepis em que essa característica está ausente.

Esses resultados certamente servirão como subsídios para futuros estudos taxonômicos buscando delimitação mais natural da seção.

\section{Referências bibliográficas}

Castro, N.M. \& Menezes, N.L. 1995. Aspectos da anatomia foliar de algumas espécies de Paepalanthus Kunth (Eriocaulaceae) da Serra do Cipó (Minas Gerais). Acta Botanica Brasilica 9: 213-229.

Chueiri-Chiaretto, I.A. 1984. Morpho-anatomical studies on leaves of species of Trimesia (Iridaceae). Hoehnea 11: 47-48.

Giulietti, A.M.; Menezes, N.L.; Pirani, J.R.; Meguro, M. \& Wanderley, M.G. 1987. Flora da Serra do Cipó, Minas Gerais: caracterização das espécies. Boletim de Botânica da Universidade de São Paulo 9: 1-152.

Giulietti, A.M. \& Hensold, N. 1990. Padrões de distribuição geográfica dos gêneros de Eriocaulaceae. Acta Botanica Brasilica 4(1): 133-159.

Giulietti, A.M.; Amaral, M.C.E. \& Bittrich, V. 1995. Phylogenetic analysis of interand and infrageneric relationships of Leiothrix Ruhland (Eriocaulaceae). Kew Bulletin 50(1): 55-71.

Giulietti, A.M.; Scatena, V.L. \& Cardoso, V.A. 1998. Anatomia de escapos e folhas e sua aplicação na taxonomia de Leiothrix flavescens (Bong.) Ruhl. S.L. (Eriocaulaceae). Sitientibus 18: 31-49.

Handro, W.; Campos, J.F.B.M. \& Oliveira, Z.M. 1970. Sobre a anatomia foliar de algumas Compostas dos campos rupestres. Ciência e Cultura 22: 107-126.

Joly, A.B. 1970. Conheça a vegetação brasileira. São Paulo, EDUSP e Polígono.

Kaiser, E. 1880. Verfahren zur Herstellung einer tadellosen Glycerin-Gelatine. Botanisch Zentralb 180: 25-26.

Koller, A.L. \& Rost, T.L. 1988. Leaf anatomy in Sansevieria (Agavaceae). Botanical Gazette 149: 260-274.

Menezes, N.L. 1971. Traqueídes de transfusão no gênero Vellozia Vand. Ciência e Cultura 23: 389-409.

Menezes, N.L. 1975. Presença de traqueídes de transfusão e bainha mestomática em Barbacenoideae (Velloziaceae). Boletim de Botânica da Universidade de São Paulo 3: 29-60.

Menezes, N.L. \& Giulietti, A.M. 1986. Serra do Cipó, paraíso dos botânicos. Ciência Hoje 4: 38-44.

Moreira, A.A.N. \& Camalier, C. 1977. Relevo. In: Geografia do Brasil. Região Sudeste. IBGE. Rio de Janeiro 3: $1-50$.
Parra, L.R. 1998. Flora da Serra do Cipó, Minas Gerais: Syngonanthus Ruhland (Eriocaulaceae). Boletim de Botânica da Universidade de São Paulo 17: 219-254.

Parkhust, D.F. 1978. The adaptative significance of stomatal occurrence on one of both surfaces of leaves. Journal of Ecology 66: 367-383.

Pyykkö, M. 1966. The leaf anatomy of East Patagonian xeromorphic plants. Annales Botanici Fennici 3: 453-622.

Roeser, K.R. 1962. Die Nadel der SchwarzkieferMassenprodukt und Kunstwert der Natur. Mikrokosmos 61: 33-36.

Rosa, M.M. \& Scatena, V.L. 2003. Floral anatomy of Eriocaulon elichrysoides and Syngonanthus caulescens (Eriocaulaceae). Flora 198: 188-199.

Sajo, M.G. 1992. Estudos morfoanatômicos em órgãos foliares de Xyrys L. (Xyridaceae). Boletim de Botânica da Universidade de São Paulo 13: 67-86.

Sajo, M.G. \& Menezes, N.L. 1994. Considerações sobre a anatomia foliar de espécies de Vernonia Screb. (Compositae) da Serra do Cipó, MG. Naturalia 19: 173-183.

Scatena, V.L. \& Menezes, N.L. 1993. Considerações sobre a natureza da câmara subestomática e das células epidérmicas das folhas de Syngonanthus Ruhl., seção Thysanocephalus Koern. (Eriocaulaceae). Revista Brasileira de Botânica 16(2): 159-165.

Scatena, V.L.; Menezes, N.L. \& Stützel, T. 1993. Embryology and seedling development in Syngonanthus rufipes Silveira (Eriocaulaceae). Beiträge zur Biologie der Pflanzen 67: 333-343.

Scatena, V.L. \& Menezes, N.L. 1995. Aspectos morfológicos e anatômicos dos caules de Syngonanthus Ruhl. (Eriocaulaceae). Boletim de Botânica da Universidade de São Paulo 14: 91-107.

Scatena, V.L. \& Rocha, C.L.M. 1995. Anatomia dos órgãos vegetativos e do escapo floral de Leiothrix crassifolia (Bong.) Ruhl., Eriocaulaceae, da Serra do Cipó - MG. Acta Botanica Brasilica 9(2): 195-211.

Scatena, V.L. \& Giulietti, A.M. 1996. The Taxonomy and morphological and anatomical differentation of populations of Leiothrix crassifolia (Eriocaulaceae). P1ant Systematic and Evolution 199: 243-258.

Scatena, V.L. \& Menezes, N.L. 1996a. Anatomia de escapos e folhas de Syngonanthus Ruhl (Eriocaulaceae). Revista Brasileira de Biologia 56(2): 317-332.

Scatena, V.L. \& Menezes, N.L. 1996b. Anatomia de raízes de Syngonanthus Ruhl (Eriocaulaceae). Revista Brasileira de Biologia 56(2): 333-343.

Scatena, V.L.; Giulietti, A.M. \& Cardoso, V.A. 1998. Anatomia do escapo floral de espécies brasileiras de Paepalanthus subgênero Platycaulon (Eriocaulaceae). Acta Botanica Brasilica 12: 121-133.

Tomlinson, P.B. 1969. III-Commelinales-Zingiberales. In: C.R. Metcalfe (ed.). Anatomy of the Monocotyledons. Oxford, Claredon Press. 